\title{
Poly-De-prescribing vs Polypharmacy - The Weapon to Fight an latrogenic Epidemic: An Overview
}

\author{
(D) Doron Garfinkel1,2 \\ ${ }^{1}$ Geriatric - Palliative consultant, Sheba Medical Center, Israel Deputy Head, Homecare Service, Israel Cancer Association, Bat Yam, Israel \\ 2IGRIMUP - The International Group for Reducing Inappropriate Medication Use \& Polypharmacy, Bat Yam, Israel
}

\begin{abstract}
This review will focus on the topic of de-prescribing, including factors which impede and promote its implementation, the attitudes of physicians and patients towards it, as well as the core recommendations of the International Group for Reducing Inappropriate Medication Use and Polypharmacy that were recently published as a position statement. Finally, I will delineate a comprehensive geriatric-palliative approach to inappropriate medication use and polypharmacy (IMUP) utilizing poly-de-prescribing-cessation of as many nonessential medications as possible. The overarching goal of this approach is minimizing harm, and improving quality of life in the twilight of life for many elderly patients. I will only briefly touch upon the problematic definitions of IMUP, the variety of their negative clinical consequences, and the key tools previously suggested for combating the epidemic, issues which have been extensively discussed and evaluated in past reviews.
\end{abstract}

Keywords: Poly-De-prescribing, polypharmacy, inappropriate medication use, palliative, dementia, frailty, quality of life, life expectancy

\section{Introduction}

Medical interventions are an inseparable part of the human experience. Using a paradigm from Genesis, the creation of Eve from Adam's rib can represent the ideal benefit/risk ratio (number needed to treat $=1$ ), while the fall from the Garden after eating from the Tree of Knowledge can represent the opposite (number needed to harm=1). Clinicians strive for the divine achievement of an ideal benefit/risk ratio, but often do not succeed, especially with regards to older patients. One particular challenge is the phenomenon of inappropriate medication use and polypharmacy (IMUP), the negative clinical, economic and social ramifications of which can be regarded as an "latrogenic epidemic" $(1,2)$ and have been reviewed extensively $(3,4)$. Given its wide-ranging importance for multiple professional fields, an improved understanding of this problem among geriatricians, internists, and generalists, as well as among non-physicians (pharmacists, nurses, policymakers, etc.) is essential. The harmful consequences of IMUP are particularly devastating in the rapidly increasing, most vulnerable geriatric subpopulations, which
I have previously termed VOCODFLEX (very old, with comorbidity, dementia, frailty/disability, and limited life expectancy) (3-5). The inability of the workforce to balance the unprecedented medical, economic, and social needs of VOCODFLEX presages a "geriatric boom catastrophe", or burden (5), and a "Tsunami in $21^{\text {st }}$ century Healthcare" (6).

It has become clear to most health professionals that IMUP are associated with diverse negative clinical outcomes that include cognitive and functional impairments, delirium, malnutrition and weight loss, falls and hip fractures, incontinence, hospitalizations, nursing home placement, decrease in quality of life ( $\mathrm{OoL})$ and quality of death, as well as medication nonadherence. Furthermore, IMUP begets IMUP in a vicious cycle of over-diagnosis and over-treatment, with the spiraling cost of drugs and hospitalizations related to adverse drug events placing unsustainable financial burdens on healthcare systems (7-17). Catastrophes and tsunamis aside, I believe that most health professionals consider IMUP to represent a major hazard to patients and health care systems. However, we as

Address for Correspondence: Doron Garfinkel MD, Geriatric - Palliative consultant, Sheba Medical Center, Israel Deputy Head, Homecare Service, Israel Cancer Association, Bat Yam, Israel and IGRIMUP - The International Group for Reducing Inappropriate Medication Use \& Polypharmacy, Bat Yam, Israel

Phone: +972-506261823 E-mail: dorong@netvision.net.il ORCID: orcid.org/0000-0002-3171-9881

Received: Mar 04, 2019 Accepted: Mar 22, 2019

Cite this article as: Garfinkel D. Poly-De-prescribing vs Polypharmacy - The Weapon to Fight an latrogenic Epidemic: An Overview. Eur J Geriatr Gerontol 2019;1(1):1-10

${ }^{\circ}$ Copyright 2019 by the Academic Geriatrics Society / European Journal of Geriatrics and Gerontology published by Galenos Publishing House. 
clinicians suffer from the illusion that we do not have a hand in propagating the problem. In reality, as I will expand upon further, we are all to blame in routinely prescribing too many medications, recommended by too many specialists, to mostly older patients, until death.

This review will focus on the topic of de-prescribing, including factors which impede and promote its implementation, the attitudes of physicians and patients towards it, as well as the core recommendations of IGRIMUP, the "International Group for Reducing Inappropriate Medication Use and Polypharmacy" that were recently published as a position statement (18). Finally, I will delineate a comprehensive Geriatric-palliative approach to IMUP utilizing poly-de-prescribing the cessation of as many nonessential medications as possible. The overarching goal of this approach is minimizing harm, and improving OoL in the twilight of life for many older patients. I will only briefly touch upon the problematic definitions of IMUP, the variety of their negative clinical consequences, and the key tools previously suggested for combating the epidemic, issues which have been extensively discussed and evaluated in past reviews.

\section{Why is the Epidemic of IMUP Emerging Now?}

The increase in average lifespan in the last century is a result of several advances in the medical sciences: improved preventative medicine, the curing of life-threatening acute illnesses, and improved management of chronic diseases. In spite of this boon, most older adults will experience a timerelated increase in the number of incurable comorbidities and disability, and the suffering they engender for prolonged periods of time prior to death $(1,3-5)$. These circumstances have yielded a rapidly-growing population of VOCODFLEX with its incumbent increase in the number of specialists involved in their care, each of whom recommend interventions based on the clinical practice guidelines of their field of expertise. Increasing sub-specialization and super-specialization within a healthcare system has clear advantages. However, when the system is fragmented, with little or no direct communication between case manager and specialist, multiple problems ensue, especially for the multi-morbid patient. From the specialist's perspective, the paramount concern is preventing morbidity or mortality from "their" disease. GPs for their part will mostly adopt the specialist's recommendations and rarely interfere or stop these treatments. The absence of a single, assertive case manager capable of looking at the big picture for VOCODFLEX, promotes confusion among patients, families, and caregivers. Lacking a multi-disciplinary or integrative approach, the physicians involved assume a passive role, projecting the burden of authority onto others (19). The result of this diffusion of responsibility is the proliferation of drugs and the interactions and adverse events that come part and parcel with them. But it doesn't end there.

\section{The Twisted Lens with which We View the Vulnerable}

Many of the great advances in medicine in the past decades are in large part due to the development and propagation of evidence-based medicine (EBM), the principles of which have led the medical community to adopt the randomizedcontrolled trial (RCT) as the gold standard of clinical research. The strongest guidelines developed by professional societies rest upon the results of multiple, large RCTs. As such, we feel secure in prescribing based upon EBM guidelines, knowing that our practice is based upon "scientific truth." While this may be true for younger, healthier patients with one, two (or even a few) medical problems, the waters become murky with regards to VOCODFLEX. Very-old age and multiple comorbidities are usually exclusion criteria in RCTs. Even when trials do include some older patients (as has recently become an FDA requirement) these patients typically do not represent the tremendous heterogeneity of VOCODFLEX (20-22). Furthermore, the same diseases in these populations behave differently. Let alone the changes in disease presentation and the physiological alterations that occur in geriatric populations, there is no longer such a thing as "natural history" of a disease as studied in medical school. These populations experience a natural history of multi-morbidity in combination with polypharmacy, a reality which changes the disease in unique ways, about which we have little to no concrete knowledge. In multi-morbid geriatric populations, this is the new norm (1). An additional key factor is that the positive benefit/risk ratio of most interventions decreases or becomes negative as older patients join the ranks of VOCODFLEX and near the end of their life expectancy. Boyd et al. (an IGRIMUP member, John Hopkins University, US) thus conclude that adhering to current guidelines in elders with comorbidities may lead to inappropriate clinical judgment, creates perverse incentives to care, and diminishes the quality of care (23). This situation is particularly prevalent and inappropriate in the frailest elderly, and in end-stage populations - where palliative care should be the main focus - it borders on the absurd (24-28). And so, despite the tenuous evidence base, we continue to implement multiple specialty-specific interventions to older patients, irrespective of extreme age and patient characteristics, and often into the palliative stages prior to death. In this way, the epidemic of IMUP was born, and nothing short of a revolution in our clinical thinking will suffice to stem the tide of this lethal problem.

\section{Defining IMUP: A Futile Debate}

Although the epidemic of IMUP has been recognized for several decades, the community of clinicians sounding the alarm has devoted an excessive amount of time and effort attempting to define the problem precisely. This includes drawing up many lists of "inappropriate drugs". While nosology is important, this approach creates a fallacy suggesting that medications 
not appearing on these lists are unconditionally "appropriate". Some use the term, "potentially inappropriate medications" (PIM). However, all medications are "potentially inappropriate" when given for the wrong indication in patients with the wrong clinical characteristics. The lack of agreement on the definition of polypharmacy - what specific number of drugs should be considered a disease in and of itself - has contributed to a long period of sterile and stagnant discussion on the topic. Polypharmacy has been vaguely defined as the "administration of more medications than are clinically indicated"; IMU as "medication use that has more potential risk for harming than potential benefit or does not agree with accepted medical standards" (29). Phrases such as "clinically-indicated" and "accepted medical standards" are problematic and dangerous in a population with a fragile evidence base. There is a fair consensus adopting the definition of Gnjidic et al. (30) (both IGIMUP members, university of Sydney, Australia) as five drugs representing the cut-off for polypharmacy, as beyond this standard, older people experience increased risk of mortality, disability, frailty and falls. However, this definition encompasses vast swathes of the population: 50\% of Medicare beneficiaries receive five or more medications (31), as do $84 \%$ of older adults with cancer, $43 \%$ receive 10 medications or more (32). In my view, cutoff numbers should not be the main concern, since IMUP can occur with even a single medication and the risk of IMUP increases in a direct relationship with the number of medications prescribed $(30,33-36)$. Given its futile nature, the time has come to close the door on the debate surrounding the definition of IMUP, and move the discourse decisively towards its effective treatment.

\section{De-prescribing in the Elderly: A Variety of Approaches}

There is no global consensus regarding the best method to combat the IMUP epidemic, but most involve de-prescribing. First introduced in 2003 by Woodward (37), the term "deprescribing" was defined as "achieving better health outcomes for older people through reducing medications". Wisely worded, this definition attacks the dogma that "the drugs are always good", and highlights the risk of too many drugs becoming a disease in itself. Reeve et al. (38) (IGRIMUP members, University of Sydney, Australia) adjusted Woodward's (37) definition, stating that de-prescribing is "the process of withdrawal of an inappropriate medication, supervised by a health care professional with the goal of managing polypharmacy and improving outcomes". As I will expand upon later, this alteration may actually introduce greater confusion, given the lack of clarity as to who adjudicates what is regarded as an IMU in an individual patient. I recommend adhering to Woodward's original definition.

Approaches to de-prescribing are traditionally classified as explicit (criteria-based) or implicit (judgment-based). Explicit tools such as lists of "Drugs to avoid" have been reviewed extensively elsewhere $(1,3,4)$ as well as in IGRIMUP's position statement (18) and will be mentioned only briefly here. Beer's lists were compiled in an attempt to quantify IMUP and have been repeatedly updated (39), but there are no controlled trials showing improved outcomes using Beers criteria. The START/ STOPP criteria (40) developed by O'Mahony et al. (41) (IGRIMUP member, Cork University, Ireland) recognize the dual nature of inappropriate prescribing by including a list of both IMU (STOPP) and the omission of potentially beneficial medications (START); they too have been updated. When applied during hospitalization STOPP/START criteria improve medication appropriateness in a statistically-significant fashion $(42,43)$. The "Fit for the Aged Criteria" (FORTA) drug classification, developed by Wheling (IGRIMUP member, University of Heidelberg Germany) ranks drugs into risk groups from A to D (44). Applying FORTA to hospitalized geriatric patients (VALFORTA) was associated with improvement of medication quality and may improve secondary clinical end points (45). This approach has already been extended to include seven European countries (EURO - FORTA) (46). Several country-specific lists have also been developed, often with a focus on the number of medications and the extent of anticholinergic effects Garfinkel et al. (3). These suffer from scant evidence of improved clinical outcomes. Steinman (IGRIMUP member, UCSF, US) concluded that while explicit tools are helpful in highlighting prescribing errors, they have several shortcomings, which render them insufficient to be considered adequate in their approach to IMUP (47). Firstly, for the most part, they have not been demonstrated in trials to improve clinical outcomes. Furthermore, in many cases of polypharmacy, it is unclear which particular drug is responsible for a given adverse effect. As well, as mentioned previously, lists of "drugs to avoid" nurture a fallacy that any drug not found on such lists is automatically appropriate.

An upgrade on the explicit approach can be found in computerized decision-making support systems. Topinkova (IGRIMUP member, Charles University, Czech Republic) (48), have demonstrated some efficacy in reducing IMUP and improved prescribing quality, claiming modest improvements in primary outcomes. The PRIMA-eDS electronic decision support tool for polypharmacy is a multinational European project led by Sönnichsen (IGRIMUP member, Witten University, Germany) and other IGRIMUP members from Finland and Spain (49). The European-funded SENATOR project developed a software engine for the assessment and optimization of drug and nondrug therapy in multi-morbid older people with polypharmacy; it was summarized in part by Soiza et al. (50) (IGRIMUP member, Aberdeen Royal Infirmary, Scotland) and other IGRIMUP members from Ireland, Spain and Belgium. While the computerized approach is a substantial leap forward in tackling the complexity of drug-drug and drug-disease interactions, 
such an approach does not address specific patient factors (pharmacogenetics, behavioral factors, etc.) which are central to the etiology of IMUP. While such programs are a useful adjunct, overreliance on them may be misleading and even harmful to elderly patients $(51,52)$.

In comparison with the explicit methods mentioned above, implicit tools are more sophisticated. They take into consideration the evidence base, clinical circumstances, and in some cases also patient preferences. The medication appropriateness index consists of ten elements considered necessary for appropriate prescribing, and demands a degree of clinical judgment. It was proven to have higher reliability and more frequently detect IMU than explicit criteria (53). The ARMOR tool incorporates patients' clinical profiles and functional status with decisionmaking and has been shown to reduce polypharmacy, healthcare costs and hospitalizations (54). The Palliative and Therapeutic Harmonization (PATH) tool has been developed by Moorhouse and Mallery (IGRIMUP members, Dalhousie University, Canada) to provide frailty-specific treatment guidelines that consider the clinical relevance of commonly-accepted outcomes in the face of multiple competing risks for mortality. Some examples of the guidance provided by this framework include cessation of medications to permit more lenient blood pressure (BP) and A1C targets, as well statin discontinuation (55-57).

Most intrinsic methods channel the principles of the Holmes (58) framework. Of its four parameters, "Treatment target" and "Goals of care" become vague in VOCODFLEX, and when "Time until benefit" for the intervention exceeds "Remaining life expectancy", preventative interventions become irrelevant. I argue that this approach should be extended to include most VOCODFLEX subgroups, which I will demonstrate in my own method later in this review.

\section{Barriers to Routine De-prescribing}

Despite the availability of multiple tools to assist the clinician in de-prescribing, this critical practice remains woefully underused. Several obstacles to de-prescribing were identified (by IGRIMUP members from İstanbul, Turkey along with myself), the main obstacle being the psychological difficulty involved in making complex treatment decisions in the face of uncertainty (3); this holds true for both practitioners and patients $(3,59)$. In the patient's perspective, the centrality of "drugs=health" can be a deep-rooted value, and de-prescribing may automatically be perceived negatively. In a given health-care encounter, patients often expect to receive a prescription at the conclusion of a medical transaction, and patient satisfaction frequently depends on this (60). Some of the fears associated with a patient's decision to discontinue a medicine may include fear of their doctor's response, of relapsing into illness, of being denied the option of subsequently resuming the medication, and of abandonment by their physician $(61,62)$. Even when physicians recommend de-prescribing, the patient may disregard this advice without specialist approval. Some even suspect attempts to de-prescribe as having economic incentives: pressure from their Healthcare organization or insurance companies to save money (3).

Physicians have their own barriers to de-prescribing. These include uncertainty over the indication for the drug (63), the excess time needed to safely de-prescribe, including discussing these complex issues with the patient/family $(64,65)$, fear of not following guidelines or specialists' recommendations, pressure due to pay-for-performance, fear of lawsuits, and fear of the patient/family's reaction (3). Some clinician responses to these issues include "I have to give the patient something", "the patient is afraid to stop medications", "if I do not prescribe, someone else will", or "having no EBM guidelines in this population, at least I adhere to guidelines that were proven in another population". All of these statements are unethical, unprofessional, and deceptive.

These various barriers may lead clinicians to a feeling of being trapped. Anthierens et al. (66) (including two IGRIMUP members from Ghent University, Belgium, stress that in spite of being aware of IMUP, and that certain treatment decisions in older patients do not represent good medical practice or beneficial patient care, GPs feel frustrated and "powerless to tackle the problem" due to the lack of guidelines for rational de-prescribing. They conclude that there is a need for simple GP-friendly tools, and access to pharmacotherapy advice to address this problem. In light of these factors, it seems likely that without the evidence and systematic frameworks to reduce IMUP, even knowledgeable and ethical clinicians lack the confidence to de-prescribe $(62,67-70)$, and thus continue to harm their most vulnerable patients, despite the very best of intentions.

\section{Moving Forward: Overcoming the Barriers}

Despite the grim picture painted above, there are signs of light on the horizon. The factors which influence effective clinical decision-making in the frail elderly are crystallizing. Lundby et al. (71) identified four themes related to health care professionals' attitudes towards de-prescribing in older people with limited life expectancy: patient and relative involvement, the importance of teamwork, health care professionals' self-assurance and skills, and the impact of organizational factors. There is a sea change in patients' attitudes as well. In contrast to a generation ago, more patients today believe that they are taking too many medications $(61,72)$ and may be open to de-prescribing. Attitudes toward IMUP have also begun to change, with drug reduction becoming increasingly recognized as a global goal of the highest priority. Several studies and reviews highlight the 
trend towards increased de-prescribing. A US-population based study evaluated the attitudes of older adults toward prescribing using a revised version of the Patients' Attitudes Towards Deprescribing questionnaire. The majority of older adults were willing to have at least one medicine de-prescribed and did not report distress surrounding this decision. Taking six or more medications was significantly associated with willingness to deprescribing (73). Todd et al. (74) (IGRIMUP member, Newcastle University, UK) have investigated de-prescribing in the palliative setting, finding that patients who have come to accept the progression of their disease tend to place less importance on their medications and less reluctant to cease them.

Education, of clinicians and patients alike, is another essential component in the fight against IMUP. In a recent systematic review, Hansen et al. (75) evaluated behavior change techniques in de-prescribing interventions.

In another review, Reeve et al. (76) concluded: "an effective patient-centered de-prescribing process will need to involve patient education on the risks and benefits of ongoing medication use, allaying any fears that patients have about medication cessation, and employing a process that includes support, monitoring and follow-up". Reeve et al. (77) also found that patient resistance to de-prescribing may be influenced by family members' attitudes as well as information acquired through the media. They recommended raising awareness about de-prescribing, discussing with the patient potential harms and benefits of given medications, informing patients about different treatment options, and culminating in joint decisionmaking. By applying these steps, patients gain confidence in the de-prescribing process (77). Sidorkiewicz et al. (78) also stress the need for continual doctor-patient dialogue to strengthen trust in the decision-making process. I would expand on these notions and claim that education about de-prescribing must begin earlier. Medical schools and residency-training programs must teach clinicians more about IMUP as well as the methods to combat it (Figure 1). These topics must become part of the core curriculum. With regards to patient education, the idea that drugs can be harmful, and may eventually need to be stopped, should be instilled early. Public awareness campaigns should be waged about the harms of IMUP and the need to deprescribe. Combined, these strategies will have a large impact on the attitudes of both clinicians and patients.

\section{Putting It All Together}

From stagnant debate about definitions and the publication of exhaustive lists, the discourse on this problem is finally starting to move into a more practical realm - how to counter the IMUP epidemic. I argue that this must take the form of the aggressive use of poly-de-prescribing - the discontinuation of as many medications as possible. To paraphrase a line from a well-known
Western: "When you have to stop - STOP, don't talk". It is with this proactive attitude which I encourage the adoption of my own approach - the Garfinkel Palliative-Geriatric Practice (GPGP) method (Figure 2). While realizing that the single, most important predictor of inappropriate prescribing is the number of prescribed medications, my approach offers an effective solution, as well as provides an appropriate definition of polyde-prescribing: "stopping as many non-life-saving drugs as possible with the approval of the patient/family".

This algorithm is simple and applicable to all patients, with any combination of comorbidities and medication, and conducive to adoption in a wide range of clinical scenarios. It emulates the original definition of EBM by Sackett et al. (79): "the integration of best research evidence, clinical expertise and patient values". The search for reliable best-evidence in VOCODFLEX may ultimately be fruitless. As such, the GPGP re-emphasizes the prominence originally intended to the latter two, forgotten pillars. GPGP combines EBM knowledge with clinical judgment, and gives high priority to patient/ family preferences. It is a palliative approach in line with the Holmes (58) framework in which medications with preventive/ curative intention of questionable value in their impact on suffering or QoL are stopped. In addition, GPGP addresses underprescribing of potentially helpful medications. Like PATH, it calls for a less aggressive approach in reaching rigid target goals (BP, serum glucose, and lipid concentrations). Given the bold nature of this intervention, all recommendations for drug discontinuation must be explained in depth and approved by the patient/family $(1-4,51)$. The high degree of involvement by the patient and families can potentially be time-consuming, but this element (in my experience) reduces the likelihood of lawsuits.

GPGP has already been implemented in both nursing departments (80) and in community-dwelling elders (51) and was beneficial in both. It has been suggested by others as a basic paradigm for addressing IMUP (81-84). The validity of the method was borne out recently in a study demonstrating improved clinical outcomes and quality of life comparing VOCODFLEX treated with GPGP with those receiving standard care (1). In this longitudinal, prospective, nonrandomized study in Israel, Poly-de-prescribing (PDP) of as many prescription drugs as possible was recommended. Poly-de-prescribing of $\geq 3$ drugs was achieved by 122 participants (PDP group); two or less drugs were stopped by 55 "non-responders" (NR group). These two groups were then compared over time. The average age was $83.4 \pm 5.3$, and $80.8 \pm 6.3$, respectively $(p=0.0045)$, and follow-up was $\geq$ three years, $43.6 \pm 14$, and $39.5 \pm 16.6$ months, respectively $(p=0.09)$. The main barrier to de-prescribing was the GPs' unwillingness to adopt PDP recommendations $(p<0.0001)$. The baseline number of medications taken by both groups was 10 (IQR 8 to 12). On the last follow up, the drug count was 11 (IOR 8 to 12) in the NR group and 4 (IQR 2 to 5) 
in the PDP group ( $p=0.0001)$. At the end of follow-up, patient/ family satisfaction, as well as clinical outcomes were evaluated based on a Likert-scale questionnaire. The PDP group showed significantly less deterioration, and sometimes improvement in the following areas: General satisfaction, functional, mental and cognitive status, sleep quality, appetite, and sphincter control. The number of major complications was significantly reduced $(p<0.002$ in all). The rate of hospitalizations and mortality was comparable. Health improvement occurred within three months after de-prescribing in $83 \%$, and persisted for $\geq$ two years in $68 \%$. This longitudinal study demonstrates in a self-selected sample that poly-de-prescribing is not only well tolerated, but also associated with improved clinical outcomes, compared with those who adhered to standard recommendations. Although cost-effectiveness has yet to be studied, intuitively GPGP seems likely to provide substantial financial savings for patients and healthcare systems alike.
The fact that this study is not a double-blinded RCT may be considered a weakness. However, I argue that researching interventions for IMUP may need different standards than those applied to trials for drugs funded by pharmaceutical companies. A "traditional" RCT in VOCODFLEX would be practically impossible. One would need to find a large cohort of demographically similar patients, stop the same $X$ number of medications within the same list of $Y$ medications prescribed for the same medical conditions, then follow both groups for several years. Logistically, the sample sizes necessary for this sort of study would be prohibitive given the great heterogeneity of VOCODFLEX, and needless to say, funding would be sparse. Yet this cannot be an excuse; we must proceed with innovative approaches for treating one of the most devastating problems our vulnerable patients face. My intention is that this study should provide a modicum of confidence to clinicians to overcome the manifold barriers to de-prescribing and get on with this critical task.

1. Perform a medication review on all older adults, particularly on vulnerable subpopulations (VOCODFLEX, D.G.) and those with polypharmacy, with an eye for de-prescribing. The need to re-prescribe discontinued medications should not be regarded as a failure.

2. Consider the generalizability of the evidence: There is underrepresentation of older adults in general, and VOCODFLEX in particular, in clinical trials. Therefore, before initiating 'appropriate' medications, consider the generalizability of the evidence for the specific patient (as also stressed in Figure 1).

3. Consider each medication for de-prescribing, extending beyond standardized lists of "inappropriate medications". Using all potentially 'helpful' medications may not be appropriate and these medications should be prioritized; in some patients, 'under-prescribing' may actual be ideal.

4. Employ mixed implicit and explicit approaches: lists of "drugs to avoid" may be helpful, but may ultimately give false assurance; other drugs that can be de-prescribed, which do not appear on the list, may be missed.

5. Communicate about the knowledge gap: Approaches to enhance de-prescribing should include recognition of the knowledge gap regarding the dose-effect curve and benefit/risk ratio of drugs used by older adults, and this uncertainty should be communicated to the patient and family.

6. Acknowledge commercial influences on polypharmacy: Publication bias and overhyping of new or immature research results by media and pharmaceutical companies result in a research narrative that overestimates efficacy, underestimates harms, and fuels IMUP. Trial results should not be implemented in older adults unless appropriate clinical outcome are proven in older populations.

7. Medical education needs a stronger focus on IMUP and its potential negative impact. Currently these topics are inadequately emphasized in the curriculum for doctors, nurses, and pharmacists. Education is insufficient regarding the harm of polypharmacy, specific drug-class ADEs, the importance of medication reviews, and how specialty prescribing may increase IMUP and lead to prescribing cascades.

\section{Medical education needs a stronger focus on combatting IMUP, including teaching methods to de-prescribe.}

9. Medical education should expand teaching on VOCODFLEX and multi-morbidity models. Current medical education places undue focus on single-disease models, and the treatment paradigms which evolve from these models may be harmful in multi-morbid patients.

10. Individualized care models for VOCODFLEX need to be developed: decision-making in older complex patients should be personalized, and must consider life expectancy, quality of life vs. burden of treatment, potential harms and benefits, and should give the highest priority to patient/family preferences. A single case manager should coordinate decisions within a shared framework, preferably in a generalist setting and ideally with the input of a pharmacist.

Figure 1. Short version of IGRIMUP 10 recommendations for action (18) 
Improving Drug Therapy in Elderly Patients - The Garfinkel Algorithm DISCUSS THE FOLLOWING WITH THE PATIENT/GUARDIAN

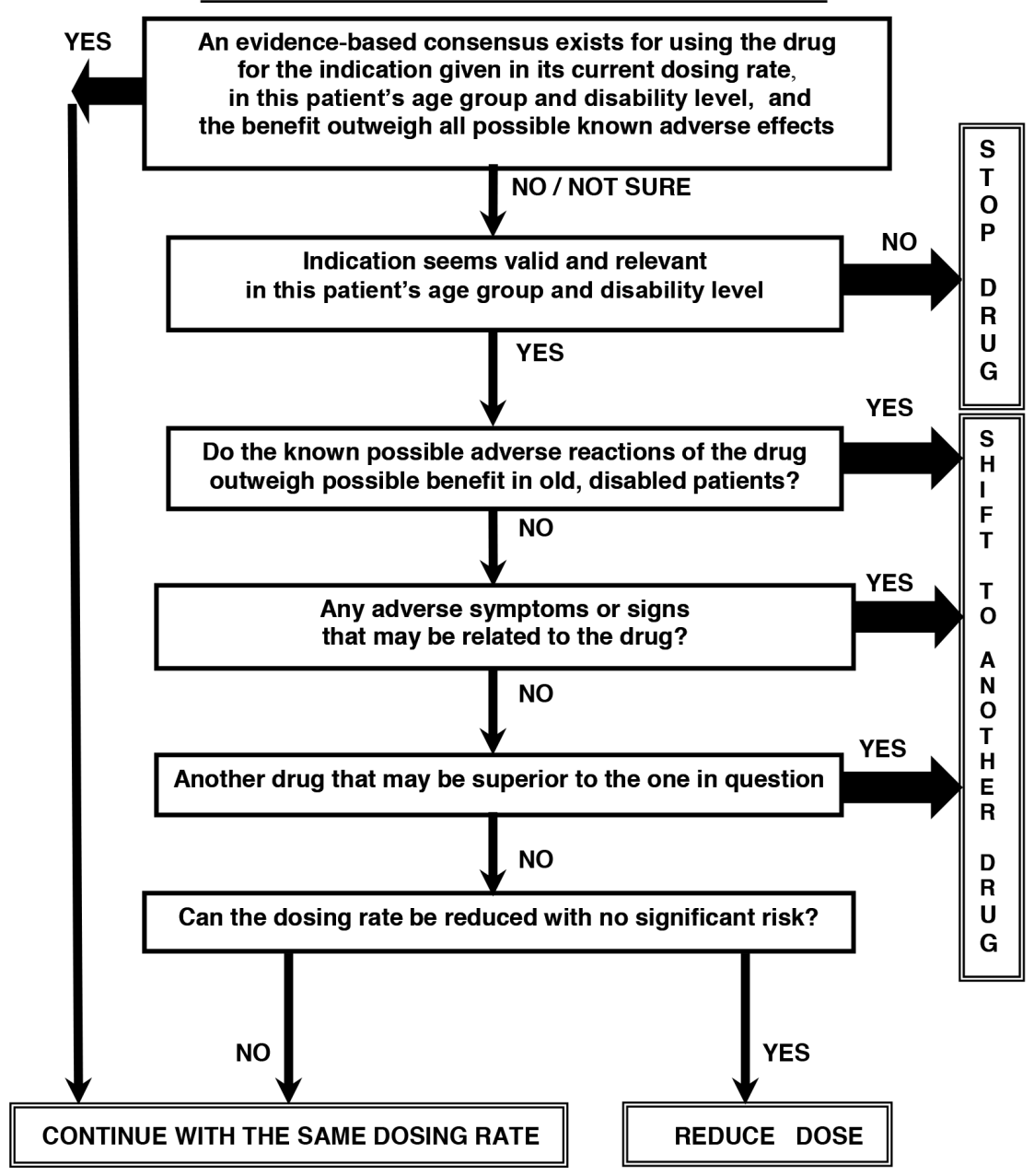

Ref: Garfinkel D, Mangin D. Feasibility study of a systematic approach for discontinuation of multiple medications in older adults - Addressing Polypharmacy. ARCH INT MED 170: 1648-54, 2010.

Figure 2. Improving Drug Therapy in Elderly Patients - The Garfinkel Algorithm

\section{A Community of Clinicians Fighting IMUP}

A milestone in the fight against the IMUP epidemic and the promotion of rational de-prescribing, was the establishment of IGRIMUP - the International Group for Reducing Inappropriate Medication Use \& Polypharmacy in 2013. Our organization's goal is to combat IMUP, via interdisciplinary communication and collaboration. IGRIMUP's membership currently numbers more than 130 leading health professionals from 30 countries joining together as a think-tank strategizing "the war against IMUP" in the conviction that, due to the tremendous extent of the problem, it should be addressed as a global pandemic $(1,2,18)$. Researchers are currently developing strategic approaches to prevent and treat IMUP in its many forms. A number of "5step de-prescribing protocols" have been proposed by several IGRIMUP members $(64,85)$, leading to a preliminary consensus regarding the principles of de-prescribing. These include reviewing all medications, identifying drugs to be stopped, substituted, or reduced, planning a de-prescribing regimen in partnership with the patient and frequently reviewing and supporting the patient (85). Recently, IGRIMUP has proposed ten comprehensive Action Recommendations, briefly summarized in figure 1. The Garfinkel GPGP method is in agreement with, and may help achieve most of these recommendations.

\section{Conclusion}

\section{Towards a New Medical Approach for the Vulnerable Elderly}

The time has come to decisively shift the focus of discourse on IMUP from definitions, evaluations, and lists of drugs to avoid towards active, rational de-prescribing. According to Scott 
(IGRIMUP member, University of Queensland, Australia), in today's atmosphere of defensive medicine and guideline-based prescribing, a large part of "doing no harm" in the geriatric population must focus on de-prescribing. We must acknowledge the knowledge gap about our patients, and avoid interventions with questionable benefit. Complex elderly patients have a vastly altered pharmacokinetic and pharmacodynamic profile, especially in the presence of comorbidity and polypharmacy; treatment decisions must be made accordingly. Partnership with the patient and family in decision-making is essential in the geriatric-palliative approach, and is key to overcoming barriers to de-prescribing. In line with these perspectives and the IGRIMUP recommendations (18), my proposed GPGP approach provides a simple and practical tool for rational, patient-centred de-prescribing. I have also provided initial evidence for the safety and practicability of the approach, as well as the many positive clinical outcomes realized by the application of GPGP.

Beyond specific definitions of IMUP and methods to combat it, a revolution in our medical paradigm in treating the elderly is of the essence. IMUP is a 21st-century iatrogenic pandemic. Like other pandemics, international efforts must be mobilized in order to manage the problem effectively, and it is in this spirit that IGRIMUP was established and has begun sowing the seeds of global collaboration of clinicians and researchers. To borrow the language of epidemics, curing the "infected", i.e. treating polypharmacy with poly-de-prescribing, is necessary but insufficient. In this review, I also emphasized "immunization", i.e. the need to educate professionals and laymen alike about this critical issue, in an attempt to stem the rising tide. The IGRIMUP principles for research, education, diagnosis, and treatment (18), are based on palliative, geriatric and ethical principles, as well as highlighting patient and family preferences, which differ in goal and in ethos from the principles of the singledisease model. We are practicing in an era when a multitude of guidelines exhort us to do a great deal of good, but we are not taught to discern when too much good becomes harm. We must uphold the legacy of generations of physicians who strove for the highest ethical standards in medical practice, and keep alight the venerable torch of "primum non-nocere".

Acknowledgment: Thanks to Dr. Aaron Bilek (Tel Aviv Sourasky Medical Centre, Israel) for assistance in the composition and editing of the article.

\section{Ethics}

Peer-review: Externally peer-reviewed.

Financial Disclosure: The author declared that this study received no financial support.

\section{References}

1. Garfinkel D. Poly-de-prescribing to treat polypharmacy: efficacy and safety. Ther Adv Drug Saf 2018;9:25-43.
2. Barnett N, Garfinkel D. Deprescribing one year on: challenging the first iatrogenic epidemic. Eur J Hosp Pharm Sci Pract 2018;25:63-64.

3. Garfinkel D, Ilhan B, Bahat G. Routine de-prescribing of chronic medications to combat polypharmacy. Ther Adv Drug Saf 2015;6:212-233.

4. Garfinkel D; IGRIMUP. Overview of Current and future research and clinical directions for drug discontinuation psychological, traditional and professional obstacles to de prescribing. Eur J Hosp Pharm Sci Pract 2017;24:16-20.

5. Garfinkel D. Geriatric Boom Catastrophe - A major medical, economic and social nightmare of the 21st century [abstract]. Proc 6th. Congress Intern Ass Gerontol Geriatr 1997:364.

6. Garfinkel D. The tsunami in 21st century healthcare: The age-related vicious circle of co-morbidity - multiple symptoms - over-diagnosis - over treatment - polypharmacy [abstract]. J Nutr Health Aging 2013;17(Suppl 1):224-227.

7. Rochon PA, Gurwitz JH. Optimising drug treatment for elderly people: the prescribing cascade. BMJ 1997;315:1096-1099.

8. Gill SS, Mamdani M, Naglie G, Streiner DL, Bronskill SE, Kopp A, Shulman KI, Lee $P E$, Rochon PA. A prescribing cascade involving cholinesterase inhibitors and anticholinergic drugs. Arch Intern Med 2005;165:808-813.

9. Spinewine A, Schmader KE, Barber N, Hughes C, Lapane KL, Swine C, Hanlon JT. Appropriate prescribing in elderly people: how well can it be measured and optimised? Lancet 2007;370:173-184.

10. Ernst FR, Grizzle AJ. Drug-related morbidity and mortality: updating the cost-of-illness model. J Am Pharm Assoc (Wash) 2001;41:192-199.

11. Hoonhout $L H$, de Bruijne $M C$, Wagner $C$, Zegers $M$, Waaijman $R$, Spreeuwenberg $P$, Asscheman $H$, van der Wal G, van Tulder MW. Direct medical costs of adverse events in Dutch hospitals. BMC Health Serv Res 2009;9:27.

12. Stark RG, John J, Leidl R. Health care use and costs of adverse drug events emerging from outpatient treatment in Germany: a modelling approach. BMC Health Serv Res 2011;11:9.

13. Rottenkolber D, Hasford J, Stausberg J. Costs of adverse drug events in German hospitals a microcosting study. Value Health 2012;15:868-875.

14. Health Data from Turkish Health Ministry (2005/2006). [http://www.sb.gov. $\mathrm{tr} / \mathrm{TR} / \mathrm{hata} / 1-0 /$ edomy $1 \mathrm{fl} 1 \mathrm{cwueh} 4500 \mathrm{xyppma}$.ex]

15. Santibanez-Beltran S, Villarreal-Rios E, Galicia-Rodriguez L, MartinezGonzalez L, Vargas-Daza ER, Ramos-Lopez JM. Economic cost of polypharmacy in the elderly in primary health car]. Rev Med Inst Mex Seguro Soc 2013;51:192-199.

16. Hovstadius B, Petersson G. The impact of increasing polypharmacy on prescribed drug expenditure-a register-based study in Sweden 2005-2009. Health Policy 2013;109:166-174.

17. Gnjidic D, Le Couteur DG, Pearson SA, McLachlan AJ, Viney R, Hilmer SN, Blyth FM, Joshy G, Banks E. High risk prescribing in older adults: prevalence, clinical and economic implications and potential for intervention at the population level. BMC Public Health 2013;13:115.

18. Mangin D, Bahat G, Golomb BA, Mallery LH, Moorhouse $P$, Onder G, Petrovic $M$, Garfinkel D. International Group for Reducing Inappropriate Medication Use \& Polypharmacy (IGRIMUP): Position Statement and Ten Recommendations for Action. Drugs Aging 2018;35:575-587.

19. Stavert RR, Lott JP. The bystander effect in medical care. N Engl J Med 2013;368:8-9.

20. Golomb BA, Chan VT, Evans MA, Koperski S, White HL, Criqui MH. The older the better: are elderly study participants more non-representative? A crosssectional analysis of clinical trial and observational study samples. BMJ Open 2012:2.

21. de Souto Barreto P, Ferrandez AM, Saliba-Serre B. Are older adults who volunteer to participate in an exercise study fitter and healthier than nonvolunteers? The participation bias of the study population. J Phys Act Health 2013;10:359-367. 
22. Sugisawa $H$, Kishino $H$, Sugihara $Y$, Shibata $H$. Characteristics of dropouts and participants in a twelve-year longitudinal research of Japanese elderly. Nippon Koshu Eisei Zasshi 2000;47:337-349.

23. Boyd CM, Darer J, Boult C, Fried LP, Boult L, Wu AW. Clinical practice guidelines and quality of care for older patients with multiple comorbid diseases: implications for pay for performance. JAMA 2005;294:716724.

24. Garfinkel D, llin N, Waller A, Torkan- Zilberman A, Zilberman N, Gurta I. Inappropriate Medication Use and Polypharmacy in end stage cancer patients: Isn't it the family doctor's role to de-prescribe much earlier?" Int J Clin Pract 2018;72:e13061.

25. Kotlinska-Lemieszek A, Paulsen O, Kaasa S, Klepstad P. Polypharmacy in patients with advanced cancer and pain: a European cross-sectional study of 2282 patients. J Pain Symptom Manage 2014;48:1145-1159.

26. Sanz Ortiz J. Chemotherapy at the end of life: up until when? Clin Transl Oncol 2012;14:667-674.

27. Cruz-Jentoft AJ, Boland B, Rexach L. Drug therapy optimization at the end of life. Drugs Aging 2012;29:511-521.

28. O'Brien CP. Withdrawing medication. Managing medical comorbidities near the end of life. Can Fam Physician 2011;57:304-307.

29. Hanlon JT, Schmader KE, Ruby CM, Weinberger M. Suboptimal prescribing in older inpatients and outpatients. J Am Geriatr Soc 2001;49:200-209.

30. Gnjidic D, Hilmer SN, Blyth FM, Naganathan V, Waite L, Seibel MJ, McLachlan AJ, Cumming RG, Handelsman DJ, Le Couteur DG. Polypharmacy cutoff and outcomes: five or more medicines were used to identify communitydwelling older men at risk of different adverse outcomes. J Clin Epidemiol 2012;65:989-995

31. Tinetti ME, Bogardus ST Jr, Agostini JV. Potential pitfalls of diseasespecific guidelines for patients with multiple conditions. N Engl J Med 2004;351:2870-2874.

32. Nightingale G, Hajjar E, Swartz K, Andrel-Sendecki J, Chapman A. Evaluation of a pharmacist-led medication assessment used to identify prevalence of and associations with polypharmacy and potentially inappropriate medication use among ambulatory senior adults with cancer. J Clin Oncol 2015;33:1453-1459.

33. Zhang X, Zhou S, Pan K Li X, Zhao X, Zhou Y, Cui Y. Potentially inappropriate medications in hospitalized older patients: a cross-sectional study using the Beers 2015 criteria versus the 2012 criteria. Clin Interv Aging 2017;12:16971703.

34. Chang CB, Lai HY, Hwang SJ, Yang SY, Wu RS, Liu HC, Chan DC. Prescription of potentially inappropriate medication to older patients presenting to the emergency department: a nationally representative population study. Sci Rep 2018;8:11727.

35. Viktil KK, Blix HS, Moger TA, Reikvam A. Polypharmacy as commonly defined is an indicator of limited value in the assessment of drug-related problems. Br J Clin Pharmacol 2007;63:187-195.

36. Rausch C, Laflamme L, Bültmann U, Möller J. Number of medications and adverse drug events by unintentional poisoning among older adults in consideration of inappropriate drug use: a Swedish population-based matched case-control study. Eur J Clin Pharmacol 2017;73:743-749.

37. Woodward MC. Deprescribing: Achieving Better Health Outcomes for Older People through Reducing Medications. J Pharm Pract Res 2003;33:323328.

38. Reeve $E$, Gnjidic $D$, Long J, Hilmer $S$. A systematic review of the emerging definition of 'deprescribing' with network analysis: implications for future research and clinical practice. Br J Clin Pharmacol 2015;80:12541268.

39. American Geriatrics Society 2015 Updated Beers Criteria Expert panel. American geriatrics society 2015 updated Beer criteria for potentially inappropriate medication use in older adults. J Am Geriatr Soc 2015;63: 2227-2246.
40. Gallagher P, O'Mahony D. STOPP (Screening Tool of Older Persons' potentially inappropriate Prescriptions): application to acutely ill elderly patients and comparison with Beers' criteria. Age Ageing 2008;37:673-679.

41. O'Mahony D, O'Sullivan D, Byrne S, O'Connor MN, Ryan C, Gallagher P. STOPP/START criteria for potentially inappropriate prescribing in older people: version 2. Age Ageing 2015;44:213-218.

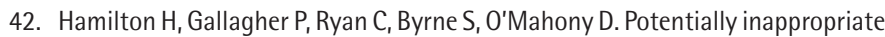
medications defined by STOPP criteria and the risk of adverse drug events in older hospitalized patients. Arch Intern Med 2011;171:1013-1019.

43. Bravo C, Peña A, Molina M, Sanfeliu J. Application of the STOPP criteria in hospitalised elderly patients to detect and optimise inappropriate psychopharmaceutical prescriptions. European Geriatric Medicine 2018:9:597-602.

44. Wehling M. Multimorbidity and polypharmacy: how to reduce the harmful drug load and yet add needed drugs in the elderly? Proposal of a new drug classification: fit for the aged. J Am Geriat Soc 2009;57:560-561.

45. Wehling $M$, Burkhardt $H$, Kuhn-Thiel $A$, Pazan $F$, Throm $C$, Weiss $C$, Frohnhofen H. VALFORTA: a randomised trial to validate the FORTA (Fit fOR The Aged) classification. Age Ageing 2016;45:262-267.

46. Pazan F, Weiss C, Wehling M; FORTA. Correction to: The EURO-FORTA (Fit fOR The Aged) List: International Consensus Validation of a Clinical Tool for Improved Drug Treatment in Older People. Drugs Aging 2018;35:677.

47. Steinman MA, Rosenthal GE, Landefeld CS, Bertenthal D, Kaboli PJ. Agreement between drugs-to-avoid criteria and expert assessments of problematic prescribing. Arch Intern Med 2009;169:1326-1332.

48. Topinkova E, Baeyens JP, Michel JP, Lang PO. Evidence-based strategies for the optimization of pharmacotherapy in older people. Drugs Aging 2012;29:477-494.

49. Renom-Guiteras A, Kunnamo I, Reeves D, Höck J, Johansson T, Sönnichsen A. The PRIMA-eDS electronic decision support tool for polypharmacy - a multinational European project. IN: Proceedings of 2017 International Association of Gerontology and Geriatrics (IAGG) 21st Word Congress; 2017 Jul 23-27, San Francisco, USA. Oxford University Press on behalf of The Gerontological Society of America, 2017.

50. Soiza RL, Subbarayan $S$, Antonio $C$, Cruz-Jentoft AJ, Petrovic $M$, Gudmundsson A, O'Mahony D. The SENATOR project: developing and trialling a novel software engine to optimize medications and nonpharmacological therapy in older people with multimorbidity and polypharmacy. Ther Adv Drug Saf 2017;8:81-85.

51. Garfinkel D, Mangin D. Feasibility study of a new systematic approach for discontinuation of multiple medications in older adults. Addressing polypharmacy. Arch Int Med 2010;170:1648-1654.

52. Garfinkel D. Digital methods for medication review - Less is more customizing drug therapy in the elderly. Europian Union Geriatric Medicine 2014;5(Suppl 1):22.

53. Hanlon JT, Schmader KE. The medication appropriateness index at 20: where it started, where it has been, and where it may be going. Drugs Aging 2013;30:893-900.

54. ARMOR: A Tool to Evaluate Polypharmacy in Elderly Persons | Annals of Long Term Care [http://www.annalsoflongtermcare.com/content/armor-atool-evaluate-polypharmacy-elderly-persons]

55. Moorhouse P, Koller K, Mallery L. End of Live Care in Frailty. Interdiscip Top Gerontol Geriatr 2015;41:151-160.

56. Mallery LH, Ransom T, Steeves B, Cook B, Dunbar P, Moorhouse P. Evidenceinformed guidelines for treating frail older adults with type 2 diabetes: from the Diabetes Care Program of Nova Scotia (DCPNS) and the Palliative and Therapeutic Harmonization (PATH) program. J Am Med Dir Assoc 2013;14:801-808.

57. Mallery LH, Allen M, Fleming I, Kelly K, Bowles S, Duncan J, Moorhouse P. Promoting higher blood pressure targets for frail older adults: a consensus guideline from Canada. Cleve Clin J Med 2014;81:427-437. 
58. Holmes HM, Hayley DC, Alexander GC, Sachs GA. Reconsidering medication appropriateness for patients late in life. Arch Intern Med 2006;166:605609

59. Reeve E, Shakib S, Hendrix I, Roberts MS, Wiese MD. The benefits and harms of de-prescribing. Med J Aust 2014;201:386-389.

60. Drug prescribing for older adults [http://www.uptodate.com/contents/ drug-prescribing-for older-adults?topicKey=PC\%2F3013\&elapsedTimeMs= 4\&view=print\&displayedView=full

61. Linsky A, Simon SR, Bokhour B. Patient perceptions of proactive medication discontinuation. Patient Educ Couns 2015;98:220-225.

62. Scott IA, Anderson K, Freeman CR, Stowasser DA. First do no harm: a real need to de-prescribe in older patients. Med J Aust 2014;201:390-392.

63. Plakiotis C, Bell JS, Jeon YH, Pond D, O'Connor DW. Deprescribing Psychotropic Medications in Aged Care Facilities: The Potential Role of Family Members. Adv Exp Med Biol 2015;821:29-43.

64. Scott IA, Hilmer SN, Reeve Potter K, Le Couteur D, Rigby D, Gnjidic $\mathrm{D}$, Del Mar CB, Roughead EE, Page A0, Jansen J, Martin JH. Reducing inappropriate polypharmacy: the process of de-prescribing. JAMA Intern Med 2015;175:827-834.

65. Reeve $E_{1}$ Turner JP. Patients' perspectives on the brave new word 'deprescribing'. Int J Pharm Pract 2015;23:90-91.

66. Anthierens $S$, Tansens A, Petrovic M, Christiaens T. Qualitative insights into general practitioners views on polypharmacy. BMC Fam Pract 2010;11:65.

67. Schuling J, Gebben H, Veehof U, Haaijer-Ruskamp FM. Deprescribing medication in very elderly patients with multimorbidity: the view of Dutch GPs. A qualitative study. BMC Fam Pract 2012;13:56.

68. Ostini R, Hegney D, Jackson C, Tett SE. Knowing how to stop: ceasing prescribing when the medicine is no longer required. J Manag Care Pharm 2012;18:68-72

69. Anderson K, Stowasser D, Freeman C, Scott I. Prescriber barriers and enablers to minimising potentially inappropriate medications in adults: a systematic review and thematic synthesis. BMJ Open 2014;4:e006544.

70. Nixon $M$, Kousgaard MB. Organising medication discontinuation: GP decision making when de-prescribing statins. BMC Health Services Research 2016) 16:226 Denmark: Copenhagen University, 2014.

71. Lundby C, Graabæk T, Ryg J, Søndergaard J, Pottegård A, Nielsen DS. Health care professionals' attitudes towards deprescribing in older patients with limited life expectancy: a systematic review. Br J Clin Pharmacol 2019;85:868-892.

72. Reeve E, Shakib S, Hendrix I, Roberts MS, Wiese MD. Review of deprescribing processes and development of an evidence-based, patientcentred de-prescribing process. Br J Clin Pharmacol 2014;78:738-747.
73. Reeve E, Wolff JL, Skehan M, Bayliss EA, Hilmer SN, Boyd CM. Assessment of Attitudes Toward Deprescribing in Older Medicare Beneficiaries in the United States. JAMA Intern Med 2018;178:1673-1680.

74. Todd A, Holmes H, Pearson S, Hughes C, Andrew I, Baker L, Husband A. 'I don't think I'd be frightened if the statins went': a phenomenological qualitative study exploring medicines use in palliative care patients, carers and healthcare professionals. BMC Palliat Care 2016;15:13.

75. Hansen CR, O'Mahony D, Kearney PM, Sahm $\sqcup$, Cullinan S, Huibers CJA, Thevelin S, Rutjes AWS, Knol W, Streit S, Byrne S . Identification of behaviour change techniques in deprescribing interventions: a systematic review and meta-analysis. Br J Clin Pharmacol 2018;84;2716-2728.

76. Reeve E, To J, Hendrix I, Shakib S, Roberts MS, Wiese MD. Patient barriers to and enablers of de-prescribing: a systematic review. Drugs Aging 2013;30:793-807.

77. Reeve $E_{1}$ Thompson W, Farrell B. Deprescribing: A narrative review of the evidence and practical recommendations for recognizing opportunities and taking action. Eur J Intern Med 2017;38:3-11.

78. Sidorkiewicz S, Tran VT, Cousyn C, Perrodeau E, Ravaud P. Discordance between drug adherence as reported by patients and drug importance as assessed by physicians. Ann Fam Med 2016;14:415-421.

79. Sackett DL, Rosenberg WM, Gray JA, Haynes RB, Richardson WS. Evidence based medicine: what it is and what it isn't. BMJ 1996:312:71-72.

80. Garfinkel D, Zur-Gil S, Ben-Israel J. The war against Polypharmacy. A new cost Effective Geriatric - Palliative approach for improving drug therapy in disabled elderly people. Israel Med Assoc J 2007;9:430-434.

81. Sengstock D, Zimmerman J. 53. Addressing Polypharmacy \& Improving Medication Adherence in Older Adults. In: Current Diagnosis and Treatment: Geriatrics 2e. In: Williams BA, Chang A, Ahalt C, Chen $\mathrm{H}$, Conant R, Landefeld CS, Ritchie C, Yukawa M. 2nd ed. McGraw-Hill Education Medical, 2014:608.

82. Ozturk Bahat G, Ozkaya H, Kılıc C, Muratli S, Ilhan B, Tufan A, Tufan $F_{\text {, }}$ Horasan Z, Dogan H, Erten N, Karan MA, Garfinkel D. P-134: Efficacy and safety of training program concentrating on the Garfinkel method as a tool for reducing polypharmacy in nursing home residents. Europ Geriat Med 2015;6(Suppl 1):1-201,

83. Scott IA, Anderson K, Freeman C. Evidence-Based Deprescribing: Reversing the Tide of Potentially Inappropriate Polypharmacy. J Clin Outc Manag (JCOM) 2016;23:359-369.

84. Campins L, Serra-Prat M, Gózalo I, Lopez D, Palomera E, Augsti C, Carbe Mi REMEI Group. Randomized controlled trial of an intervention to improve drug appropriateness in community-dwelling polymedicated elderly people. Fam Prac 2016;34:36-42.

85. Farrel B, Mangin D. Deprescribing is an essential part of good prescribing Am Fam Physician 2019;99:7-9. 